Elaine Cristina Marqueze ${ }^{2}$

Claudia Roberta de Castro Moreno ${ }^{3}$

\section{Satisfação no trabalho - uma breve revisão ${ }^{1}$}

\section{Job satisfaction - a short review}

${ }^{1}$ Trabalho extraído da Dissertação de Mestrado de Elaine Cristina Marqueze intitulada Satisfação no trabalho e capacidade para o trabalho de docentes de uma instituição de ensino superior, defendida em 2005 na Universidade do Sul de Santa Catarina (Unisul).

${ }^{2}$ Profissional de Educação, Professora da Universidade do Extremo Sul Catarinense (Unesc).

${ }^{3}$ Bióloga, Professora do Programa de Pós-Graduação em Saúde Coletiva da Universidade do Sul de Santa Catarina (Unisul).

\section{Resumo}

Este artigo tem o objetivo de apresentar uma breve revisão sobre satisfação no trabalho, analisando suas diferentes concepções. Associadas a essas concepções, também são apresentadas características do trabalho que interferem e determinam a satisfação, bem como as conseqüências da satisfação e da insatisfação no ambiente de trabalho.

Palavras-chaves: satisfação no trabalho, saúde do trabalhador, trabalho.

\section{Abstract}

The purpose of this article is to present a short review of work satisfaction, analyzing its different conceptions. Associated to such conceptions we also present work characteristics that interfere and determine satisfaction, as well as the consequences of satisfaction and non-satisfaction at the work environment.

Keywords: job satisfaction, occupational health, job. 


\section{Introdução}

A avaliação de um sistema de trabalho se dá a partir da capacidade de adaptação do trabalho ao homem e do homem ao trabalho (GUÉRIN et al., 1997; DEJOURS, 2002). Um dos aspectos que interfere na capacidade de adaptação é a satisfação no trabalho, que, segundo Rohmert (apud FISCHER \& PARAGUAY, 1989), refere-se à integração, à autonomia, à motivação, ao envolvimento e à utilização das capacidades físicas e mentais.

O comportamento humano no ambiente de trabalho vem sendo amplamente estudado nos últimos tempos, destacando-se no aspecto emocional a satisfação que o trabalhador possui em sua atividade. Segundo Klijn (1998), desde os anos 30, pes-

\section{Metodologia}

A pesquisa foi estruturada a partir da revisão bibliográfica sobre o tema satisfação no trabalho, tendo como palavra-chave de busca satisfação no trabalho.

As fontes de busca foram restritas aos acervos das bibliotecas da Universidade Federal de Santa Catarina, Universidade do Sul de Santa Catarina e Universidade do Extremo Sul Catarinense; aos materiais em meio digital, disponibilizados nos sites das universidades públicas do Brasil, bem como aos sites SCIELO, biblioteca digital

\section{Resultados}

Diversas concepções sobre a satisfação no trabalho foram encontradas na literatura consultada. A determinação da satisfação no trabalho e suas conseqüências na saúde do trabalhador nem sempre são claras. Alguns fatores podem atuar tanto como determinante quanto como conseqüência da satisfação, a exemplo do relacionamento com os colegas de trabalho. Em determinada situação, se este aspecto estiver negativo, ele pode gerar insatisfação no trabalho. Por outro lado, a insatisfação no trabalho pode gerar problemas de relacionamento no ambiente de trabalho.

Diversos autores identificam alguns fatores como determinantes (exemplo: fatores sócio-demográficos) e outros como conseqüências (exemplo: prejuízos à saúde) a fim de facilitar medidas de intervenção. quisadores realizam estudos sobre o tema satisfação no trabalho, posto a relevância deste aspecto no ambiente de trabalho e na saúde do trabalhador. (LOCKE, 1969; HERZBERG, 1971; HENNE \& LOCKE, 1985; BERGAMINI \& BERALDO, 1988; HARRIS, 1989; FRASER, 1996; BEGLEY \& CZAJKA, 1993; BÜSSING et al., 1999; ELOVAINIO et al., 2000; WRIGHT \& CROPANZANO, 2000; O’DRISCOLL \& BEEHR, 2000; REGO, 2001; ROBBINS, 2002; MARTINEZ, 2002).

O objetivo do presente trabalho é fazer uma revisão das diferentes concepções sobre satisfação no trabalho, assim como identificar seus determinantes e suas conseqüências na saúde do trabalhador.

de teses e dissertações da USP, DEDALUS e LILACS.

O período de coleta de materiais foi entre 2004 e 2005, não sendo estabelecida limitação dos anos revisados, sendo encontrados um total de 337 bibliografias sobre satisfação no trabalho. Realizou-se uma triagem, excluindo os materiais referentes à gestão e à administração, selecionando apenas os relacionados à área de saúde do trabalhador e que atendesse ao objetivo estabelecido.
Portanto, com base nos autores pesquisados, este artigo apresentará os determinantes e as conseqüências da satisfação separadamente, com o intuito de possibilitar a compreensão das distintas concepções sobre a satisfação no trabalho.

\section{Concepções da satisfação no trabalho}

Locke (1969) define satisfação no trabalho como o resultado da avaliação que o trabalhador tem sobre o seu trabalho ou a realização de seus valores por meio dessa atividade, sendo uma emoção positiva de bem-estar. Vale ressaltar que esse autor difere valores de necessidades, em que necessidades referem-se à sobrevivência e ao bem-estar do indivíduo, sendo essas inatas e comuns a todos, e os valores são diferentes de pessoa para pessoa, pois 
vai ao encontro do que o indivíduo deseja ou percebe como benéfico (LOCKE, 1969, 1976). Segundo Locke (1969, 1976), a satisfação no trabalho é um estado emocional, porque a emoção deriva da avaliação dos valores do indivíduo, e por tratar-se de um estado emocional, a satisfação possui dois fenômenos: o de alegria (satisfação) e o de sofrimento, desprazer (insatisfação).

Apesar de Locke $(1969,1976)$ relatar que a satisfação no trabalho é um fenômeno individual, ressalta que os fatores causais podem ser classificados em dois grandes grupos: eventos e condições do trabalho (trabalho propriamente dito, pagamento, promoção, reconhecimento, condições de trabalho, ambiente de trabalho); e agentes do trabalho (colegas e subordinados, supervisores, empresa/organização), assinalando que os fatores causais devem ser analisados em suas inter-relações.

Locke (1976) refere que a satisfação no trabalho pode gerar conseqüências tanto para o indivíduo como para a organização, afetando aspectos comportamentais e a saúde física e mental do trabalhador.

Para Harris (1989), a satisfação no trabalho é um sentimento que resulta da situação total do trabalho. Fraser (1996) apresenta satisfação no trabalho como um estado pessoal, subjetivo, dinâmico e constantemente modificável por condições intrínsecas e extrínsecas do trabalho e do trabalhador.

Locke (1969, 1976), Henne \& Locke (1985), Begley \& Czajka (1993), Elovainio et al. (2000) e O'Driscoll \& Beehr (2000) concordam que satisfação e insatisfação no trabalho fazem parte de um mesmo fenômeno, não sendo desassociados. Martinez (2002, p.17) aponta que essa concepção considera que a satisfação e a insatisfação, estão em um contínuo, em que a satisfação encontra-se em um extremo e a insatisfação em outro, "não dando suporte à concepção de dois contínuos unipolares independentes (um pertencendo à satisfação e outro, à insatisfação)".

Algumas definições sobre o tema satisfaÇão no trabalho apresentam-se divergentes. Alguns autores consideram como um estado emocional, um sentimento, conforme apresentado anteriormente (LOCKE, 1969, 1976; HENNE \& LOCKE, 1985; HARRIS, 1989; BEGLEY \& CZAJKA, 1993; FRASER, 1996; WRIGHT \& CROPANZANO, 2000; ELOVAINIO et al., 2000; O'DRISCOLL \& BEEHR, 2000). Outros consideram satisfação como uma atitude (REGO, 2001; ROBBINS, 2002). Essas diferenças podem resultar em erros metodológicos de pesquisa e devem ser observadas e consideradas quando da escolha do instrumento de medida para ir ao encontro dos objetivos propostos.

Para Rego (2001), a satisfação no trabalho está relacionada ao tratamento de justiça e de respeito a que o trabalhador é submetido. Já Robbins (2002, p.74) define satisfação no trabalho "como a atitude geral de uma pessoa em relação ao trabalho que realiza". Esse autor assim define pois considera que o homem possui uma reação ativa às situações de trabalho que não o satisfazem, deliberando atitudes de mudanças. Esta concepção aborda a satisfação e a insatisfação no trabalho como fenômenos distintos, sendo que a insatisfação está relacionada aos fatores que determinam o trabalho, como ambiente, recompensas e chefia, sendo essa concepção baseada na Teoria de Herzberg (HERZBERG, 1971).

Locke $(1969,1976)$ aponta falhas em algumas teorias desse tema, como a de Herzberg, que considera satisfação e insatisfação fenômenos distintos, não indicando as diferenças individuais de percepção da satisfação no trabalho, justificando essa falha com a afirmativa de que os valores são pessoais, sendo emocionais os principais determinantes no trabalho.

Para Bergamini \& Beraldo (1988), as definições sobre satisfação no trabalho, independentemente da concepção abordada, só possuem valia se consideradas as diferenças individuais resultantes das variáveis inatas em interação com as experiências vividas.

Sendo a satisfação no trabalho influenciada pela capacidade de enfrentamento de situações diversas (HARRIS, 1989), ou seja, tornando-se dinâmico o processo de satisfação, envolvem-se situações variadas, características de personalidade, situações de trabalho, expectativas, necessidades e motivações (BÜSSING et al., 1999). Desta forma, uma única área de estudo não consegue abranger toda a complexidade desse tema e, por isso, pode-se observar que ele é abordado tanto pelas áreas sociais como pela saúde.

Essas duas áreas partem do pressuposto de que, para a análise dos determinantes da satisfação no trabalho, devem ser considerados dois componentes: o componente afetivo emocional (relacionado ao sentimento de como a pessoa se sente no 
trabalho) e o componente cognitivo (a racionalidade do indivíduo sobre o trabalho), conforme Locke (1969, 1976). Essa análise está em concordância com a definição de satisfação no trabalho como um estado emocional (LOCKE, 1969, 1976; HENNE \& LOCKE, 1985; HARRIS, 1989; BEGLEY \& CZAJKA, 1993; FRASER, 1996; WRIGHT \& CROPANZANO, 2000; ELOVAINIO et al., 2000; O’DRISCOLL \& BEEHR, 2000).

Neste primeiro momento, a abordagem das concepções existentes sobre satisfação no trabalho é para ressaltar suas diferenças, sem o propósito de se determinar a melhor concepção.

Independentemente da concepção adotada de satisfação no trabalho, não há como negar que este aspecto interfere no processo saúde-doença e conseqüentemente no ambiente de trabalho e na vida pessoal dos trabalhadores.

\section{Determinantes da satisfação no trabalho}

Para Bauk (1985), os fatores considerados como os mais significantes ao estresse e à insatisfação no trabalho são a falta de conhecimento sobre oportunidades de progresso e promoção no trabalho e o modo como ocorre a avaliação da performance profissional. Outros fatores são a carga de trabalho excessiva, a interferência do trabalho na vida particular, a carência de autoridade e influência necessárias à execução de seu trabalho.

Sneed \& Herman (1990), em pesquisa com trabalhadores do serviço de alimen- tação de um hospital, verificaram associação estatisticamente significativa entre satisfação no trabalho e concessão de bons salários e benefícios, bom relacionamento social no trabalho (envolvendo chefia e colegas), perspectivas de crescimento profissional dentro da organização e, também, com as características de trabalho.

A partir de um levantamento de estudos sobre esse tema, Cavanagh (1992) também apresentou fatores que poderiam determiná-lo. O primeiro estudo analisado por Cavanagh (1992) foi o de Locke e Gruneberg, em que foram identificados três aspectos influenciadores da satisfação no trabalho: diferenças na personalidade, diferenças no trabalho e diferenças nos valores atribuídos ao trabalho. A seguir, Cavanagh (1992) cita os estudos de Hinshaw e Atwood e de Weissman et al., em que ambos identificam como fatores de influência na satisfação no trabalho: a idade, o sexo, a inteligência, o nível educacional, a experiência, o nível hierárquico, o status profissional, a autonomia de trabalho, a repetição imposta, a tarefa executada, a remuneração e o resultado do trabalho.

Utilizando os fatores citados por esses estudos, Cavanagh (1992, p.707) realizou um estudo com 221 enfermeiras chefes de um hospital, apresentando, como resultado final, um modelo teórico das variáveis relacionadas à satisfação no trabalho (Figura 1), em que há associações positivas e associações negativas definidas a partir dos testes de Correlação de Pearson e da Covariância de Matrix.

Relações Positivas

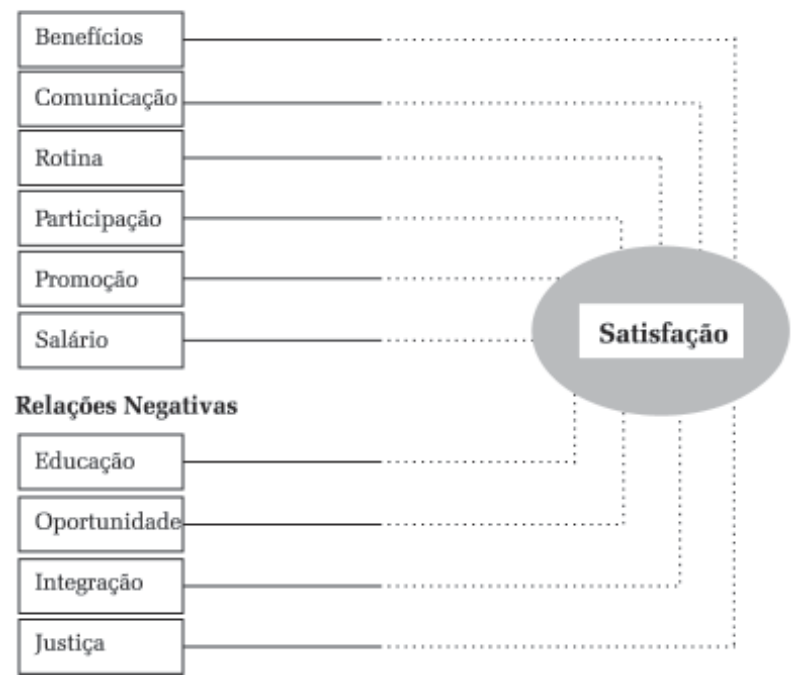

Figura 1 Modelo teórico de conexão entre variáveis selecionadas e satisfação no trabalho.

Fonte: CAVANAGH, S. J. Job satisfaction of nursing staff working in hospitals. Journal of Advanced Nursing, v. 17, n. 6, p. 704-711, 1992. 
Dejours (1994) afirma que, se o trabalho for de livre escolha e organizado, ele proporciona equilíbrio e prazer, já que possibilita a descarga da carga psíquica. Dessa forma, identificar quais os componentes do trabalho que se opõem à descarga de energia é uma maneira de proporcionar motivação e satisfação no trabalho.

Em estudo realizado por Estefano (1996) sobre a satisfação dos funcionários (total de 88) da biblioteca central da Universidade Federal de Santa Catarina, verificou-se que o principal fator responsável pela insatisfação desses funcionários constitui-se nas condições de trabalho, sendo que os aspectos que mais contribuíram para a satisfação foram às relações interpessoais e o trabalho em si.

Em estudo realizado por Gonçalves (1996) com 25 docentes universitários, é verificado que as atuais formas de organização do trabalho negam a satisfação e a autonomia do trabalhador.

Em estudo realizado por Ramires et al. (1996) sobre saúde mental em médicos, sendo a maioria homens (88\%) e casados (95\%), relacionando os efeitos do estresse sobre satisfação no trabalho, foi constatado que um baixo nível de estresse exerce um efeito de proteção na satisfação; e a satisfação no trabalho possui um efeito de proteção à saúde mental, especificamente no estresse ocupacional dos entrevistados.

Peterson \& Dunnagan (1998), avaliando o impacto de um programa de promoção à saúde desenvolvido com funcionários de uma universidade do norte dos Estados Unidos, verificaram que o grau de instrução apresentou relação positiva com a satisfação no trabalho, visto que quem possui um maior grau de instrução possui também um maior grau de decisão em relação ao trabalho realizado. Neste mesmo estudo, os autores constataram associação estatisticamente significativa entre satisfação no trabalho e estimulação intelectual proveniente do trabalho, boa gerência e disponibilidade de recursos para o desenvolvimento do trabalho, boa posição profissional (nível hierárquico) e bons relacionamentos com o público atendido. No aspecto individual, foram a autonomia e o trabalho diversificado (PETERSON \& DUNNAGAN, 1998).

Também foi constatado que o estilo de vida - no que se refere ao consumo de álcool, uso de tabaco, técnicas de redução do estresse e prática de atividade física na ocasião da pesquisa e com um tempo de prática menor do que seis meses - não apresentou relação significativa com a satisfação no trabalho. A participação em programas de bem-estar, que incluem atividade física, controle alimentar e educação para a saúde, também não influenciou nos níveis de satisfação no trabalho, mas relacionou-se com a diminuição dos riscos em adquirir doenças (PETERSON \& DUNNAGAN, 1998)

Um outro fato é que quem participa desses programas tende a engajar-se em programas regulares de atividades físicas e, conseqüentemente, pode melhorar sua satisfação no trabalho. Esse estudo também apresentou diferença significativa na satisfação no trabalho entre aqueles que referenciaram participar de programas de exercícios físicos há pelo menos seis meses em relação àqueles que não participavam, e isso independentemente da participação em outros programas de promoção à saúde. Ou seja: a satisfação no trabalho era maior para quem participava de programas de exercícios físicos há pelo menos seis meses (PETERSON \& DUNNAGAN, 1998), o que remete ao seguinte questionamento: "A saúde influencia a satisfação no trabalho?" ou "A satisfação facilita a saúde?" (PETERSON \& DUNNAGAN, 1998, p. 977). Portanto, o incremento de comportamentos positivos relacionados à saúde, no que se refere ao aumento da satisfação no trabalho, ainda não é consistente.

Esteve (1999), em seus estudos sobre o mal-estar docente, constatou que, quando a imagem pública de uma profissão se deteriora, diminui a satisfação no trabalho dos profissionais que a exercem, apontando que, na década de 70 , uma cifra de $30 \%$ de professores estava insatisfeita com sua profissão (NATIONAL EDUCATION ASSOCIATION apud ESTEVE, 1999).

Litt \& Turk (apud ESTEVE, 1999), em pesquisa realizada com 291 professores, constataram que as maiores fontes de insatisfação no trabalho são os salários inadequados, o baixo status social da profissão (que inclui o mau comportamento dos alunos e as poucas oportunidades para progredir) e o excesso de trabalho a ser realizado em pouco tempo.

Para Büssing et al. (1999), a maioria dos estudos que apresentaram hipóteses formuladas relacionadas ao tema satisfação no trabalho não fornece estrutura teórica de embasamento, neles se constatando a 
realização de estudos metodologicamente incorretos, pois em vários se verificaram níveis elevados de satisfação no trabalho em ambientes com aspectos inadequados, tais como insalubridade, altos níveis de acidente de trabalho e de absenteísmo e trabalho fragmentado.

Korunka \& Vitouch (1999), em seu estudo sobre os efeitos da implementação de uma nova tecnologia de informação em trabalhadores de uma companhia de processamento eletrônico de Viena, verificaram que a satisfação no trabalho está favoravelmente associada à estabilidade no emprego, a salários e benefícios, relacionamento social no trabalho, relacionamento com a chefia, perspectivas de carreira, ambiente físico do trabalho e bons prazos para resolução dos processos de trabalho.

Os bons relacionamentos sociais no ambiente de trabalho e com a chefia também possuíram associação estatisticamente significativa com a satisfação no trabalho no estudo de Wright \& Cropanzano (2000).

Relação positiva também foi encontrada no que se refere à estabilidade no emprego, a salário e benefícios, relacionamento com a chefia e oportunidade de desenvolvimento profissional no estudo realizado por Elovainio et al. (2000) com profissionais da saúde de hospitais da Finlândia.

Elovainio et al. (2000) apresentaram vários estudos que demonstraram associação estatisticamente significativa entre controle sobre o trabalho $\mathrm{x}$ autonomia exercida e alta tensão ocupacional x baixa satisfação no trabalho. Em seu estudo descrito anteriormente, estes autores constataram que o controle sobre o trabalho é responsável pela maioria das variações na satisfação no trabalho tanto dentro da organização como no plano individual. Verificaram também que a satisfação no trabalho e a saúde mental estão estatisticamente relacionadas, bem como as características individuais e organizacionais, demonstrando relação positiva entre aspectos psicossociais específicos do ambiente de trabalho (controle sobre o trabalho - fator de maior importância) e aspectos de personalidade. Dessa forma, Elovainio et al. (2000) apresentaram estudos que afirmam que ter o controle do trabalho é um fator de proteção para problemas de saúde.

Fatores como estabilidade no emprego, salário e benefícios, relacionamento social no trabalho, relacionamento com a chefia, carga física e mental do trabalho, perspecti- va de carreira, ambiente físico do trabalho, rotina de trabalho (variedade/monotonia), desafios no trabalho, autonomia e oportunidade de desenvolvimento profissional também foram verificados por O'Driscoll \& Beehr (2000) no estudo realizado com 236 trabalhadores de duas firmas de contabilidade - uma dos Estados Unidos e outra da Nova Zelândia - como determinantes da satisfação no trabalho.

No estudo de Rego (2001) com docentes do ensino superior sobre percepções de justiça, o autor constatou que os docentes tratados com justiça e respeito apresentaram menor intenção de abandonar o trabalho, um maior comportamento de cidadania organizacional, maior satisfação, faltavam menos, apresentavam melhores níveis de desempenho individual, maior empenho, confiança e comprometimento com o trabalho, além de maior apego e lealdade à empresa.

Martinez (2002), em seu estudo com técnicos e analistas de uma empresa de administração e gerenciamento de planos de previdência privada e de saúde, verificou que $65,2 \%$ dos pesquisados apresentaram associação estatisticamente significativa da satisfação no trabalho (avaliada pelo Occupational Stress Indicator - OSI) com o cargo de trabalho (melhor nível hierárquico) e o tempo de empresa (menor tempo na empresa), sendo que as variáveis idade, sexo, renda, escolaridade e estado civil não apresentaram associação.

Borges \& Argolo (2002) apresentaram os estudos desenvolvidos por Borges, Cavalcanti \& Portela, em 1999 e 2000, com 75 petroleiros do Pólo Guamaré (RN), utilizando o Inventário de Prazer e Sofrimento no Trabalho (IPST), em que estes autores constataram associação dos valores organizacionais (Igualitarismo e Domínio/Harmonia) e dos fatores de prazer e sofrimento com a percepção de satisfação no trabalho.

Maciel (2002) constatou, em seu estudo sobre os fatores interferentes na satisfação dos trabalhadores de uma unidade de alimentação e nutrição hospitalar, que as condições de trabalho, na unidade pesquisada, também interferem na satisfação de seus trabalhadores.

De acordo com o exposto, os fatores intervenientes na satisfação no trabalho são diversos, merecendo mais estudos sobre o tema para que alternativas e soluções possam ser criadas. Segundo Martinez (2002), não se deve ignorar as diferenças e as per- 
cepções individuais, pois essas determinam a satisfação no trabalho e estão inseridas em um contexto histórico e cultural, que possuem valores e oportunidades.

Não há, portanto, um único fator determinante para a satisfação; estes dependem do ambiente e das condições de trabalho, bem como da avaliação pessoal do trabalhador. No entanto, identificá-los é crucial para se efetivar programas de melhoria da satisfação no trabalho.

\section{Conseqüências da satisfação e da insatis-} fação no trabalho

Estar ou não satisfeito em relação ao trabalho incorre em conseqüências diversas, sejam elas no plano pessoal ou profissional, afetando diretamente o comportamento, a saúde e o bem-estar do trabalhador. Essa afirmativa é baseada no modelo das conseqüências da insatisfação no trabalho proposto por Henne \& Locke (1985), em que a insatisfação no trabalho pode gerar conseqüências na vida individual, na saúde mental e na saúde física desse indivíduo.

Os primeiros estudos sobre o tema referenciam a satisfação e a insatisfação e suas conseqüências na saúde e no bem-estar do trabalhador fornecendo suposições de que a insatisfação no trabalho pode estar relacionada ao estresse ocupacional (RAHMAN \& SEM, 1987). Os autores Rahman \& Sem (1987) afirmam que o absenteísmo é menor entre os que possuem uma maior satisfação no trabalho.

Os autores também apontam que a satisfação no trabalho possui grande influência na determinação dos níveis de estresse e na qualidade de vida do trabalhador, sendo que o trabalho, quando possui fatores estressantes e de insatisfação, freqüentemente se torna uma verdadeira prisão em decorrência das más condições em que é executado. E, quando ele é associado a programas de prevenção e promoção da saúde, pode e deve ser fonte de satisfação e de realização.

Em referência à relação da satisfação no trabalho e ao estresse ocupacional, Henne \& Locke (1985) relatam que a insatisfação no trabalho conduz ao estresse.

Alguns estudos relataram que a satisfação no trabalho apresenta conseqüências à saúde mental, como o de Rahman \& Sem (1987), que realizaram pesquisa com 82 trabalhadores de uma fábrica, com idade média de 34 anos. Estes tinham uma média de 14 anos de experiência profissional, nível primário de educação e realizavam trabalho repetitivo. No referido estudo, foi constatada associação significativa entre satisfação no trabalho e saúde mental, pois os resultados indicaram que quem tinha uma maior satisfação no trabalho estava em um estado de saúde mental melhor, isso em comparação aos que tinham uma baixa satisfação no trabalho. Além disso, quem estava com um melhor estado de saúde também tinha maior satisfação no trabalho. Estudos de Caplan et al. e Roman \& Trice (apud RAHMAN \& SEM, 1987) também apontaram essa associação.

Benito (1994), em seu estudo sobre a análise de exigências cognitivas das atividades do trabalhador de enfermagem, relatou que a satisfação no trabalho apresenta influência favorável no desenvolvimento do trabalho de enfermeiras.

Segundo estudo conduzido por Hipwell et al. (apud PETERSON \& DUNNAGAN, 1998), a insatisfação no trabalho contribui para o estresse ocupacional e ambos contribuem para um efeito negativo à saúde.

Algumas tentativas são realizadas para minimizar essas questões, uma delas é a promoção de atividades de redução do estresse, que, para Peterson \& Dunnagan (1998), não produzem impacto favorável à satisfação no trabalho, pois, para esses autores, estresse e satisfação no trabalho são fatores desassociados.

Silva et al.(1998) argumentam que, no ambiente de trabalho, algumas condições podem representar sobrecargas no sentido de estresse, e uma delas é a insatisfação no trabalho decorrente do conteúdo e da carga de trabalho, em que uma maior insatisfação leva a uma maior sobrecarga de estresse.

Zalewska (1999), em seu estudo sobre a importância dos relacionamentos sociais nos aspectos do trabalho e na satisfação no trabalho, aponta que a satisfação no trabalho conduz à melhor saúde física e mental, relatando que ocorre uma menor incidência de doenças em trabalhadores satisfeitos e, conseqüentemente, uma melhor qualidade de vida desses.

O’Driscoll \& Beehr (2000) também encontraram associação estatisticamente significativa entre satisfação no trabalho e saúde mental, sendo que uma maior satisfação remete a um menor número de queixas de saúde. A insatisfação está relacionada à incerteza, a conflitos de papéis no contexto do trabalho e a pressões no ambiente de trabalho (O’DRISCOLL \& BEEHR, 2000). 
Tyrer, citado por Gazzotti \& Codo (2002), salienta que baixos índices de satisfação no trabalho estão associados a uma maior incidência dos sintomas de lesões por esforços repetitivos.

Martinez (2002), em estudo já relatado, aponta também alguns efeitos comportamentais conseqüentes da insatisfação no trabalho verificados em sua pesquisa: absenteísmo, rotatividade, atrasos ou pausas prolongadas e/ou não autorizadas, queda da produtividade, protestos ou greves e insatisfação com a vida de acordo com a importância que o trabalho possui na vida do indivíduo. Há de considerar-se que essas respostas são individuais e variadas.

Rahman \& Sem (1987), Büssing et al. (1999), Rego (2001) e Martinez (2002) apresentam que trabalhadores satisfeitos possuem um menor número de absenteísmo. Em contradição, Robbins (2002), em seu livro sobre comportamento organizacional, aponta relação negativa entre satisfação e absenteísmo, justificando que funcionários satisfeitos, desde que não sofram penalidades, também podem faltar na mesma proporção que os funcionários insatisfeitos, sendo fator determinante para o absenteísmo os fatores de influência, como cobrança e penalidades e não necessariamente a satisfação no trabalho.

Jardim et al. (2004) fazem menção à associação estatisticamente significativa entre satisfação no trabalho e síndrome de Burnout (síndrome de esgotamento profissional), ou seja, a insatisfação no trabalho é preditora para a síndrome de Burnout, síndrome esta que freqüentemente afeta profissionais da saúde e da educação, sendo uma resposta ao estresse laboral crônico.

Robbins (2002) relata também a relação negativa entre satisfação e rotatividade no trabalho, pois existem outros fatores de influência na decisão de abandonar o emprego. Segundo o autor, o fator que exerce relação direta e forte para que não ocorra a rotatividade é o desempenho do trabalhador, o que conseqüentemente gera grandes esforços do empregador para manter este funcionário.

Robbins (2002) apresenta outras reações além do abandono do emprego como expressão de sua insatisfação, como: alguns reagem tendo ações de negligência, não fazendo nada para que a situação se modifique, esperando passivamente pela sua melhoria; outros, ao contrário, realizam tentativas ativas e construtivas para melhorar as condições de trabalho.
A condição de felicidade dos funcionários, como determinante para uma maior produção, é apontada como falsa por Robbins (2002), que apresenta resultados de correlação baixa entre esses dois aspectos. Afirma, ainda, que seria mais verdadeiro o inverso, funcionários produtivos tendem a ser funcionários felizes, o que, conseqüentemente, pode significar recompensas do tipo reconhecimento, aumento de remuneração, promoções etc., remetendo à relação entre satisfação e produtividade. Segundo Robbins (2002), há necessidade de estudos sobre a satisfação no trabalho que focalizem o estado de saúde dos trabalhadores.

Foi proposto por Galbraith (apud SELIGMANN-SILVA, 2004) a "cultura do contentamento" nas organizações e na sociedade em geral, sendo esta cultura sinônimo de saúde mental. Os insatisfeitos são vistos com desconfiança e discriminação, pois perturbam o "mundo feliz e eficaz", e como pessoas com capacidades produtiva e cognitiva duvidosas. Assim, muitos trabalhadores negam e ocultam suas decepções, seus mal-estares e suas dores psíquicas e físicas, resultando em disfarces convincentes da insatisfação no trabalho. Esses disfarces muitas vezes são mantidos com o uso de estimulantes psicofármacos, álcool ou drogas.

A relação entre satisfação no trabalho, uma menor carga mental e um maior comprometimento com o trabalho não é tão simples nem tão fácil de mensurar, por isso a necessidade de se pesquisarem todas as variáveis possivelmente relacionadas, bem como as diversas áreas que o trabalho abrange. Há de ressalvar-se que o sofrimento psíquico não é linear, pois depende do contexto, da história de vida e do encadeamento dos eventos em uma situação concreta. O sofrimento psíquico foi responsável, na década de 90, pela segunda causa de afastamento no trabalho (JACQUES \& CODO, 2002).

Assim como os determinantes, as conseqüências da satisfação no trabalho também são individuais e variadas, abrangendo os planos pessoal e profissional, sendo unânime a constatação de que os fatores psicossociais do trabalho interferem nos processos saúde-doença. Medidas de promoção à saúde devem ser adotadas visando a minimizar as dificuldades enfrentadas pelos trabalhadores quanto aos bem-estares orgânico e social, posto que a satisfação no trabalho deve ser considerada como um determinante de saúde. 


\section{Comentários Finais}

Pode-se então concluir que as concepções de satisfação no trabalho mais amplamente aceitas e divulgadas no meio científico são as que contemplam a importância dos aspectos psicossociais no trabalho, em que a combinação de acontecimentos ou circunstâncias, num dado momento, determina a satisfação no trabalho, corroborando a Teoria de Locke, desenvolvida no final da década de 60 ((LOCKE, 1969).

O processo de satisfação no trabalho resulta da complexa e dinâmica interação das condições gerais de vida, das relações de trabalho, do processo de trabalho e do controle que os próprios trabalhadores possuem sobre suas condições de vida e trabalho. A satisfação no trabalho pode ser, por conseguinte, fonte de saúde, bem como a insatisfação pode gerar prejuízos à saúde física, mental e social, acarretando problemas à organização e ao ambiente de trabalho.

Diante dos fatores abordados sobre satisfação no trabalho, fica evidente que não

\section{Referências Bibliográficas}

BEGLEY, T. M.; \& CZAJKA, J. M. Panel analysis of the moderating effects of commitment on job satisfaction, intent to quit, and health following organizational change. Journal of Applied Psychology, v. 78, n. 4, p. 552-556, 1993.

BENITO, G. A. V. Análise de exigências cognitivas das atividades do trabalhador de enfermagem. 1994. Dissertação (Mestrado em Enfermagem) - Programa de Pós-Graduação em Enfermagem de Florianópolis, Universidade Federal de Santa Catarina, Florianópolis.

BERGAMINI, C. W.; \& BERALDO, D. G. R. Avaliação do desempenho humano na empresa. 4ed. São Paulo: Atlas, 1988.

BORGES, L. O.; \& ARGOLO, J. C. T. Estratégias organizacionais na promoção da saúde mental do indivíduo podem ser eficazes? In: JACQUES, M. G.; \& CODO, W. (orgs.). Saúde mental \& trabalho: leituras. Petrópolis: Vozes, 2002.

BÜSSING, A. et al. A dynamic model of work satisfaction: qualitative approaches. Human Relations. v. 52, n. 8, p. 999-1003, 1999. há apenas um único aspecto, mas uma complexa rede de recursos que podem ser implantados e modificados visando à promoção da saúde dos trabalhadores.

Medidas coletivas devem ser efetivadas para amenizar os problemas decorrentes da insatisfação no trabalho. Dentre essas, sugere-se adaptação do ambiente de trabalho ao homem; aumento das oportunidades para atividades de lazer, esporte e relaxamento; atividades sociais; programas de interação social; adequação do salário à função exercida; plano de carreira; cumprimento das leis trabalhistas; formação de uma equipe de saúde ocupacional para avaliar as situações de risco, adotando medidas preventivas e de apoio, entre outras. É importante acrescentar ainda a necessidade da participação dos trabalhadores em todo o processo, o qual deve ser realizado por meio de ações interdisciplinares e de alcance coletivo com o intuito de atuar na manutenção e na promoção da saúde do trabalhador.

CAVANAGH, S. J. Job satisfaction of nursing staff working in hospitals. Journal of Advanced Nursing. v. 17, n. 6, p. 704-711, 1992.

DEJOURS, C. A carga psíquica do trabalho. In: BETIOL, M. I. S. (coord.) Psicodinâmica do trabalho: contribuições da Escola Dejouriana à análise da relação prazer, sofrimento e trabalho. 3ed. São Paulo: Atlas, 1994. p. 21-32.

. O fator humano. Rio de Janeiro: Fundação Getúlio Vargas, 2002.

ELOVAINIO, M. et al. Organizational and individual factors affecting mental health and job satisfaction: a multilevel analysis of job control and personality. Journal of Occupational Health Psychology. v. 5, n. 2, p. 269-277, 2000.

ESTEFANO, E. V. V. Satisfação dos recursos humanos no trabalho: um estudo de caso na biblioteca central da Universidade Federal de Santa Catarina. 1996. Dissertação (Mestrado) - Programa de Pós-Graduação do Centro Tecnológico de Florianópolis, Universidade Federal de Santa Catarina, Florianópolis. 
ESTEVE, J. M. O mal-estar docente: a sala de aula e a saúde dos professores. Tradução: Durley de Carvalho Cavicchia. Bauru: Edusc, 1999.

FISCHER, F. M.; \& PARAGUAY, A. I. B. B. A ergonomia como instrumento de pesquisa e melhoria das condições de vida e trabalho. In: FISCHER, F. M.; GOMES, J. R.; \& COLACIOPPO, S. (coord.). Tópicos de saúde do trabalhador. São Paulo: Hucitec, 1989.

FRASER, T. M. Work, fatigue, and ergonomics. In: INTRODUCTION to industrial ergonomics: a textbook for students and managers (online). Toronto: Wall and Emerson, 1996. Available from: http://www. wallbooks.com/source/fraser.htm. Access in: 2003 fev 10.

GAZZOTTI, A.; \& CODO, W. Histeria: doença profissional. In: JACQUES, M. G.; \& CODO, W. (orgs.). Saúde mental \& trabaIho: leituras. Petrópolis: Vozes, 2002.

GONÇALVES, D. C. O discurso sobre as relações educação-saúde-trabalho, de professores universitários e trabalhadores da construção civil. 1996. Dissertação (Mestrado em Engenharia de Produção e Sistemas) - Programa de Pós-Graduação em Engenharia de Produção e Sistemas de Florianópolis, Universidade Federal de Santa Catarina, Florianópolis.

GUÉRIN, F. et al. Compreender o trabalho para transformá-lo: a prática da ergonomia. Tradução: Giliane M. J. Ingratta, Marcos Maffei. São Paulo: Edgard Blücher, 1997.

HARRIS, R. B. Reviewing nursing stress according to a proposed coping-adaption framework. Advances in Nursing Science. v. 11 , n. 2, p. 12-28, 1989,

HENNE, D.; \& LOCKE, E. Job dissatisfaction: what are the consequences? International Journal of Psychology. v. 20, p. 221240, 1985.

HERZBERG, F. Work and the nature of man. $4^{\text {th }}$ ed. Cleveland: World Publishing, 1971.

JACQUES, M. G.; \& CODO, W. Saúde mental $\&$ trabalho: leituras. Petrópolis: Vozes, 2002.

JARDIM, S. R.; SILVA FILHO, J. F.; \& RAMOS, A. O diagnóstico de Burnout na atenção em saúde mental dos trabalhadores. In: ARAÚJO, A. et al. (orgs.). Cenários do trabalho: subjetividade, movimento e enigma. Rio de Janeiro: DP\&A, 2004.

KLIJN, T. M. P. Satisfação no trabalho de mulheres acadêmicas da Universidade de Concepción. 1998. Tese (Doutorado) - Es- cola de Enfermagem de Ribeirão Preto e Escola de Enfermagem da Universidade de São Paulo, Chile.

KORUNKA, C.; \& VITOUCH, O. Effects of the implementation of information technology on employees strain and job satisfaction: a context-dependent approach. Work and Stress. v. 34, n. 4, p. 341-363, 1999.

LOCKE, E. A. What is job satisfaction? Organizational Behaviour Human Performance. v. 4, n. 4, p. 309-336, 1969.

. The nature and causes of job satisfaction. In: DUNNETTE M. D. (ed.). Handbook of industrial and organizational psychology. Chicago: Rand McNally, 1976. p. 1297-1349.

MACIEL, T. R. S. Fatores interferentes na satisfação dos trabalhadores de uma unidade de alimentação e nutrição hospitalar. 2002. Dissertação (Mestrado em Engenharia de Produção e Sistemas) - Programa de Pós-Graduação em Engenharia de Produção e Sistemas de Florianópolis, Universidade Federal de Santa Catarina, Florianópolis.

MARTINEZ, M. C. As relações entre a satisfação com aspectos psicossociais no trabalho e a saúde do trabalhador. 2002. Dissertação (Mestrado em Saúde Ambiental) - Programa de Pós-Graduação do Departamento de Saúde Ambiental, Faculdade de Saúde Pública, Universidade de São Paulo, São Paulo.

O'DRISCOLL, M. P.; \& BEEHR, T. A. Moderating effects of perceived control and need for clarity on the relationship between role stressors and employee affective reactions. The Journal of Social Psychology. v. 140, n. 2, p. 151-159, 2000.

PETERSON, M.; \& DUNNAGAN, T. Analysis of a worksite health promotion program's impact on job satisfaction. Journal Occupational Environ. Medicine. v. 40, n. 11, p. 973-979, 1998.

RAHMAN, M.; \& SEM, A. K. Effect of job satisfaction on stress, performance and health in self-paced repetitive work. Int. Arch. Occup. Environ. Health. v. 59, n. 2, p. 115-121, 1987.

RAMIRES, A. J. et al. Mental health of hospital consultants: the effects of stress and satisfaction at work. The Lancet. v. 347, n. 9003, p. 724-728, 1996.

REGO, A. Percepções de justiça: estudos de dimensionalização com professores do ensino superior. Psic.: Teor. e Pesq. (online). v. 17, n. 2, p. 119-131, 2001. Dis- 
ponível em: http://www.scielo.br/scielo. php?script $=$ sci_arttext\&pid $=$ S0102-37722 $001000200004 \& \operatorname{lng}=\mathrm{pt} \& \mathrm{nrm}=\mathrm{iso}$. Acesso em: 06 jan. 2006.

ROBBINS, S. P. Comportamento organizacional. 9ed. São Paulo: Prentice Hall, 2002.

SELIGMANN-SILVA, E. Os riscos da insensibilidade. In: ARAÚJO, A. et al. (orgs.). Cenários do trabalho: subjetividade, movimento e enigma. Rio de Janeiro: DP\&A 2004.

SILVA, G. C.; FERREIRA, J. C. M.; \& YAMAOKA, T. Stress e trabalho. 1998. Monografia (Especialização em Medicina do Trabalho) - Curso de Especialização em Medicina do Trabalho de Florianópolis,
Universidade Federal de Santa Catarina, Florianópolis.

SNEED, J.; \& HERMAN, C. M. Influence of job characteristics and organizational commitment on job satisfaction of hospital foodservice employees. Journal of the American Dietetic Association. v. 90, n. 8, p. 1072-1076, 1990.

WRIGHT, T. A.; \& CROPANZANO, R. Psychological well-being and job satisfaction as predictors of job performance. Journal of Occupational Health Psychology. v. 5, n. 1, p. 84-94, 2000.

ZALEWSKA, A. M. Achievement and social relations values as conditions of the importance of work aspects and job satisfaction. Int. Occup. Saf. Ergon. v. 5, n. 3, p. 395-416, 1999. 